\title{
The Governance of Low-Carbon Transitions in a Multilevel Perspective Framework: How Does the Concept of 'System Transformation' Work?
}

\author{
Liying Li \\ Department of Geography and Environment, \\ London School of Economics and Political Sciences, London WC2A 2AE, UK
}

Article history

Received: 02-10-2020

Revised: 05-12-2020

Accepted: 28-12-2020

Email: liliying88@gmail.com

\begin{abstract}
The energy studies on low carbon transition provide valuable insights into the characteristics of socio-technological transitions and the driving factors of appropriate policy intervention. Transition studies have adopted the multilevel perspective framework to inform policymaking and to assess policies for sustainable transitions. Policymakers face challenges in trying to reconcile innovation and sustainability policy objectives. How can the concept of "system transformation" assist policymakers in combining innovation and sustainability goals and building a sustainable innovation policy regime? We reviewed various system transition publications and examined the role that policymakers can play in solving issues arising in the process of shaping system transition to sustainability with the system transformation concept. This paper will provide some determinants of success for niche innovations, regime setting and legitimacy making in a multilevel perspective framework to support policymakers.
\end{abstract}

Keywords: System Transformation, Multilevel Perspective, SocioTechnological Regimes, Niche, Low Carbon Transitions

\section{Introduction}

Since the industrial revolution, the economy's thirst for energy has never been slaked. With the carbon footprint of the traditional technology system, global climate change is becoming more and more indisputable. Persistent problems like global climate change are difficult to manage, hard to grasp and operate at different scale levels (Rotmans et al., 2001). Effective climate change mitigation will require simultaneous system transformation toward renewable electricity, sustainable agriculture, green transport and other systems, amongst which low carbon transition of energy systems is a key.

Low-carbon transitions to decarbonize the economy are goal-oriented in addressing the problems of climate change are different from historical "emergent" transitions since for historical transition, entrepreneurs are exploiting the commercial opportunities offered by new technology (Geels et al., 2017). Persistent problems like climate change in energy and other systems are usually deeply rooted in our societal structures and unsolved by traditional short-term policy approaches (Djalante and Djalante, 2012). Many obstacles are affecting the effectiveness of policy implementation to facilitate systemic long term low carbon transitions, such as uncertainty about cause-effect relations, dis-centralized control power, ambivalence about goals, political myopia and the danger of carbon lock-in (Kemp et al., 2007). Low carbon transitions globally have been becoming more challenging in recent years since the developing regions catch up with carbon emissions with increasing energy use to sustain economic development. The theories of dominant catch-up and convergence suggested that innovations and thereby also transitions should travel from the West to the rest of the world by means of technology transfer (Jolly et al., 2012; Köhler et al., 2019). Accordingly, studies are exploring how innovations for inclusive development induce sustainability transitions, especially in low-income contexts (Smith and Seyfang, 2013; Onsongo, 2019).

The guiding principles to develop a sustainable innovation policy should combine systems thinking and dealing with the complexity and systemic interactions of low-carbon transformation and policy-making (Foxon and Pearson, 2008).

The multilevel perspective has been developed to deal with persistent problems in interaction with policymakers (Rotmans et al., 2001). The innovation system for low carbon transitions can be defined as the set of actors and 
rules that influence the speed and direction of technological change in a specific technological area (Charles, 2005). The multilevel perspective has absorbed plenty of research interest so far to lead the road to the renewable energy system and a carbon-neutral world (Geels et al., 2017; Geels, 2002; Rip and Kemp, 1998; Smith et al., 2005; Geels et al., 2018). Against this background, we nail to the reasoning on how the "system transformation" informs the policymakers to pack up the effective policy set pursuing the goal of long-term carbon reduction in energy systems. In this study, we exclusively talked about the system transformation in the framework of a multilevel perspective.

To pave a pathway from a high-carbon "here" to a sustainable low-carbon "there", public policy must play a central role by changing socio-economic conditions (via taxes, subsidies, standards and regulations) and supporting the emergence and deployment of lowcarbon innovations (Geels et al., 2017). We assume that the concept of "system transformation" can assist policymakers getting through this process thus achieving a far-reaching low-carbon transition goal. First of all, it leads us to an appropriate mix policy institution and promotes broader participation through building networks. It takes the bond of different actors and their interaction into the policy-making process; thus, all the actors can practice with a concerted goal. Secondly, it helps the social-technology out of lock-in with system thinking and dealing uncertainties of longterm goals in the level of niche development, making a radical technology innovation possible to come into existence. It drives a bottom-up legitimacy making for a long-term radical sustainable transition. Finally, the system transformation concept attracts attention to socio-technological landscape and multilevel interaction dynamics, facilitating the understanding of the impacts of the wider landscape context on transition niches and regimes. We will spread our backup for each of the three propositions in the three levels of a multilevel perspective.

\section{A Multilevel Perspective: Analytical Framework}

System transition researchers inform innovation policy and evaluate policy implementations through a framework of a Multilevel Perspective (MLP) (Fig. 1). (Kern and Smith, 2008; Kern, 2012) MLP regards wideranging processes of social technological change as embedded within wider institutional, economic and social parameters. Geels suggests that a multilevel perspective can be fruitfully adopted to understand socio-technological system transition through three levels: Socio-technological landscape, sociotechnological regime and niche. System transitions occur through interactions between developments on all three levels (Geels, 2004).

\section{Socio-Technological Landscape}

The socio-technological landscape represents the wider condition, which influences both niche and regime dynamics. The landscape-level comprises slowly changing external factors such as climate change, which are beyond the control of individual actors; however, influence the development of the energy system and low carbon transitions. The socio-technological landscape includes spatial structures (e.g., urban layouts), political ideologies, societal values, beliefs, concerns, the media landscape and macroeconomic trends.

\section{Socio-Technological Regime}

The socio-technological transition system actors are embedded in socio-technical regimes and don't act in a vacuum. Actor behavior is constrained by rules located at the collective level of a regime, which cannot easily be changed at the micro-level of individual action (Rip and Kemp, 1998). The socio-technological regime is characterized by a dominant configuration of institutions, user practices, market structures, certain technological conditions, regulatory frameworks, cultural preferences and scientific knowledge. The notion of socio-technical regimes encompasses all social groups, including manufacturers, engineers, users, policymakers and civil society actors. The notion of 'regimes' refers to more intangible rules on which actors draw in concrete actions (Geels, 2012).

\section{Niche Level}

Niche actors work on radical innovations that deviate from existing regimes. On the niche level, new low carbon technologies such as renewable energy technologies emerge in protected spaces or market niches, evolve and possibly start to compete with the dominant regime (Kern, 2012).

\section{Box 1}

Analytical framework of this paper to answer the question: How does the concept of 'system transformation' work?

\section{Niche level}

1. Provide space for niche development

2. Building networks for stakeholders

3. Dealing with uncertainties

\section{Regime level}

4. Prepare appropriate policy mix for transitions

5. Integrate and manage window opportunities

6. Guide the direction of market formation

Socio-technological landscape level

7. Help understand the multilevel interaction dynamics 
Increasing structuration of activities in local practices

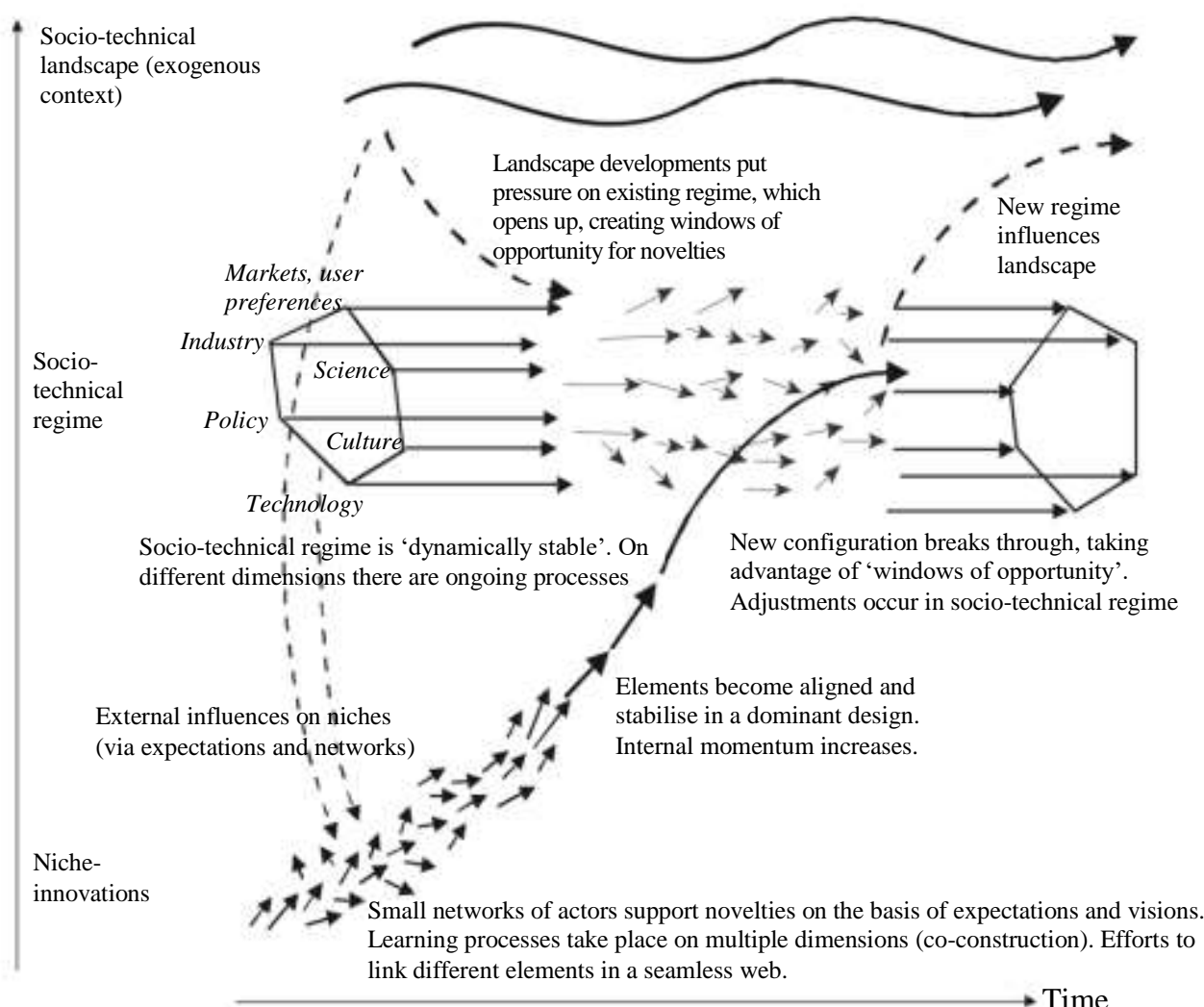

Fig. 1: Socio-technical transitions from a multi-level perspective. Source (Geels and Schot, 2007)

However, the existing regime is stabilized by many lockin mechanisms; thus, it is not easy for novelties to overturn incumbent technological regimes.

We use the multilevel perspective as an analytical framework in our paper because the interaction between industry, technology, markets, policy, culture and civil society can be clearly presented in a Multilevel Perspective framework (MLP) (Geels, 2012).

\section{Understanding Obstacles for Low Carbon Transition}

There are systems weaknesses that occur while implement low carbon transitions pointed by many empirical and theoretical studies (Negro et al., 2012; Purkus et al., 2018). Low carbon transition is contested; thus, a certain level of legitimacy is required for actors to commit to the new technology with investment, adoption decisions. For example, if an institution is soft, there may lack legitimacy, so actors like entrepreneurs or investors disagree about the desirability of different lowcarbon paths and often resist their implementation (e.g., onshore wind turbines, carbon storage and carbon capture). However, if an institution is hard, there is an uncertain policy environment making entrepreneurs and investors reluctant to take the risk and invest in renewable energy technologies. Structural change in energy systems is difficult in terms of political implementation, making it difficult to combine the nurturing of niches with 'control policies' to disturb the existing regime and undermine policymakers' constructive engagement in the low carbon transitions.

Low-carbon transitions are also disruptive processes (Geels et al., 2017). They are disruptive to the economic positions and business models of the powerful incumbent industries. Refrains on the core technologies of the current regime create losers and e.g., regional unemployment problems (Jänicke and Jacob, 2005). The developments also had unintended negative consequences such as native companies may be rendered disadvantage in the global market and go bankrupt due to increased energy prices, which eroded the strength of the green growth discourse.

Low carbon transitions are non-linear because climate change policies and low-carbon transformation can experience setbacks, accelerations, or disappointment after 
a period of hype (e.g., current climate policies in the UK, USA and Australia) (Geels et al., 2017). If the transitions approach is captured by the incumbent energy regime, the original ambition will be undermined for making radical energy system innovation. This capture has the consequence that pathways and niches of the system transformation fit into the existing high carbon regime; hereby, only optimization of the existing socio-technical system is realized instead of structural change contributing to a new sustainable energy system (Kern and Smith, 2008).

System transformation is useful for analyzing which systemic problems hamper the development and diffusion of innovations and learning the right point for policy intervention (Kanger et al., 2020), facilitating policymaking processes. We look through the detailed function of system transformation in the next sections in a framework of a multilevel perspective.

\section{Niche Level}

\section{Provide Space for Niche Development}

The alignment of technology regimes provides stability for technology development. The downside of this stability has been termed 'lock-in' (Unruh, 2000). Due to path dependence, industrial economies have become locked into fossil fuel-based energy systems, driven by the system or network externalities. As an effect of technological and institutional increasing returns to scale, technologies are closely linked to their socio-economical environment. The system failures were comparable to lock-in, namely institutional failures, failures in infrastructure provision and investment, all of which can serve as signposts for policymakers to make an intervention. Policies play an important role in guiding the direction of socio-technological transformation, to break the lock-in into the dominant socio-technical regime level.

With a viewpoint of system transformation, the energy policy's incentives should be created to facilitate the R\&D of new technology from a niche level. New energy system practices and innovations such as renewable energy technologies emerge in protected spaces or market niches, evolve over time and possibly 'overturn' the dominant regime (Kern, 2011).

With the concept of system transformation, policymakers can reduce uncertainty for investors and entrepreneurs through creating collective expectations and implement a technology selection environment with societal aims that align distributed technology choices. In achieving this, the credibility and stability of are of: Policymakers should avoid frequent and rapid shifts of policies and emphasize the central importance of credible and stable transition policies. Otherwise, individual actor may disincline to undertake investments whose payoff depends on the realization of a path transition (Hekkert and Negro, 2009).

Innovation system reflects that individual technologies change relatively rapidly, whilst technological systems tend to change relatively slowly since innovation and diffusion is a systemic, dynamic, non-linear process. The concept of system transformation makes policymakers recognized that little allowance is made for nonlinearities and threshold effects of technological transition if only the process of technological development and climate change are modeled. Therefore System transformation can empower policymakers to make more informed energy policy and evaluate more accurately, strategically creating protection for innovation experiments via pilot projects or making spaces available for developers (Holtz et al., 2018).

\section{Building Networks for Stakeholders}

The diversification of policy instruments required by system transformation makes the task of making and implementing policy not only a mission for the public sectors but also the responsibility of private firms. This may pose the problem of distributed control for system transformation. The system transformation uses the creation of networks and platforms of private and public actors to make policymakers able tackle the issue of distributed control in the process of transitions to low carbon systems. The network and platforms perform the role of identifying attractive transition visions, paths and, finally, the fostering of coalitions for transition experiments.

The transition approach itself is seen as a learning process by all the actors involved. Networks were built up across different levels of innovation systems, ensuring broad stakeholder participation, facilitating information exchange and mutual learning process. Active participation of both public and private actors creates complementary elements, contributing to a more sustainable future. Policymakers can learn about what is effective and what is not, both in terms of mixes of instruments and technologies. The transition system uses pilot projects to identify the roles stakeholders want the government to play to support the transition, expecting commitment and partnership from the government (Nieto et al., 2014).

It is sensible to bring broader stakeholders into participation in appropriate policy-making processes. Thus, government, market and society can also set policy aims jointly. E.g., ministries setting up 'one-stop shops' for advice and problem-solving; public actors playing a crucial role in opportunities making and doing experimentation. In the case of the Dutch Transition Approach (Kemp et al., 2007), which can be adapted elsewhere, we can see such an cooperation relationship 
between policymakers and market exist. Building networks of public and private actors can promote public/private institutional structures to enhance regulator/regulated relationships and stakeholder activities.

Besides the cooperation relationship, policymakers can support knowledge diffusion and resource mobilization. They can support feedback processes such as pilot and demonstration plants in the form of $R \& D$ and investment support, but also deployment support; examples are government-funded test centers or publicly supported clusters (Gallagher et al., 2012).

\section{Dealing with Uncertainties}

The transition approach can help with dealing with uncertainties and avoiding apparent certainties. The government is not Instead of 'choosing' specific options, the government organizes its policy around a cluster of options: The transition paths. Market players will have the opportunity to develop their products based on their culture, expertise, expectation, market analysis and ambitions.

Over the long-term transition of the energy system, no single technology can solve such an interdisciplinary issue. Many social aspects need to be considered, such as human behavior, social acceptability, economic costs, infrastructure issues, innovation stimulation and reliability of markets and governance. As a result, a combination of a variety of transition themes and paths is of great value to resolve the uncertainties in innovation system transformation. The concept of system transformation helps policymakers deal with uncertainties by using a scenario analysis while preparing future low-carbon technologies. Various transition paths are developed in several years. The system thinking suggests conducting 'transition experiments' to test alternative paths of energy practices and technologies. In theory, experiments are characterized by a high risk of failure as well as high potential (Rotmans et al., 2001) and policymakers should utilize a dedicated system risk assessment tool in developing policy support instruments. Decision-makers of public and private sectors determine which paths should be finally implemented. Take the case of the Dutch energy transition policy as an example (Table 1); there are 28 transition paths developed in 6 years.

Next, the criteria used for path determination can affect the significance of the transition system to bring about social or institutional changes. Kern and Smith (2008) argue that the dominance of business actors and the dominant aim of the transition system to create new energy businesses led to a focus on (technological) innovation on the supply side rather than a long-term transition towards a sustainable energy system. Policymakers should base the selection of transition pathways on diverse criteria such as the three-stage multicriteria analysis, taking broader sustainability criteria into account. Therefore, the system transformation can encompass a balanced niche portfolio with a strong element of public and stakeholder engagement.

Table 1: Dutch energy transition: Themes, goals and paths (Source: (Kemp et al., 2007))

\begin{tabular}{|c|c|c|}
\hline Theme & Goal & Transition path \\
\hline Green resources & $\begin{array}{l}\text { Substitution of } 30 \% \text { of resources for energy } \\
\text { by green resources by } 2030\end{array}$ & $\begin{array}{l}\text { Biomass production in NL } \\
\text { Chains for biomass import WISE Biomass co-production } \\
\text { Synthetic Natural Gas Sustainable chemistry }\end{array}$ \\
\hline Sustainable mobility & $\begin{array}{l}\text { Factor } 2 \text { reduction of GHG emissions for new } \\
\text { vehicles in } 2015 \text { and factor } 3 \text { reduction for all } \\
\text { vehicles in } 2030\end{array}$ & $\begin{array}{l}\text { Biofuels } \\
\text { Hybrid propulsion } \\
\text { Hydrogen vehicles } \\
\text { Intelligent transport systems }\end{array}$ \\
\hline New gas & $\begin{array}{l}\text { To become the most sustainable gas country } \\
\text { in Europe }\end{array}$ & $\begin{array}{l}\text { Energy efficient greenhouses } \\
\text { Decentralized electricity generation } \\
\text { Green gas hydrogen clean fossil fuels }\end{array}$ \\
\hline Built environment & $\begin{array}{l}\text { To accelerate energy improvement programs } \\
\text { and stimulate new innovations }\end{array}$ & $\begin{array}{l}\text { Removal of institutional barriers } \\
\text { Development and implementation of innovations } \\
\text { Energy improvements in } \\
\text { built environment }\end{array}$ \\
\hline Chain efficiency & $\begin{array}{l}20-30 \% \text { extra improvement of product } \\
\text { chains by } 2030\end{array}$ & $\begin{array}{l}\text { Clearing house for bulk products } \\
\text { Process intensification Multimodal transport } \\
\text { Symbiosis (closing material optimizing the waste chain } \\
\text { Precision farming loops) Micro cogeneration } \\
\text { Energy efficient paper production }\end{array}$ \\
\hline $\begin{array}{l}\text { Sustainable } \\
\text { electricity supply }\end{array}$ & To make electricity supply more sustainable & $\begin{array}{l}\text { Renewable energy sources decarburization and } \\
\text { cogeneration electric infrastructure } \\
\text { Electricity use }\end{array}$ \\
\hline
\end{tabular}




\section{Regime Level}

\section{Prepare Appropriate Mix of Policy Instruments}

Policymakers want to develop a synergistic, integrated mix of policy instruments that cohere to balance benefits and costs of likely economic, environmental and social impacts and promote sustainable transformation. Policy mixes are a set of policy goals, strategies and instruments that influence a given system. Policy mixes will experience a consistent shift in the evolution of system innovation (Kanger et al., 2020). As for energy policy instruments, policy interventions to address one issue are likely to have otherwise unanticipated effects on other instruments due to lack of integration in the design of the mixes. For instance, innovation policy can be deal with the market failure that innovators cannot appropriate the full benefits of their investment in creating that knowledge. So that private firms can have sufficient incentives to undertake innovation to systematically efficient levels. Environmental policy can target the problem with 'externalities', providing policy instruments in aspects of economics and regulations (such as taxes, emissions trading schemes, emission or technology standards) to 'internalize' those externalities (Purkus et al., 2018). These separate regimes of innovation and environmental are unlikely to address the challenge of persistent problems like climate change adequately.

Theoretical and empirical studies on how system transformation comes up with an appropriate policy mix have attracted researchers' attention (Purkus et al., 2018; ICEPT, E4Tech, 2003; Foxon and Pearson, 2007). Without the concept of system transformation, it will be inadequately represented that the whole picture of innovation is a dynamic, systemic, non-linear process involving significant uncertainties. The system thinking will help to understand the current models of innovation and diffusion processes so that policymakers can assess instruments in terms of appropriateness to stages of the transition process and supports not only innovative niches but increases pressure on incumbent regimes as well. A systems viewpoint and greater awareness of this can help avoid unanticipated consequences or conflicts between policies of different areas, promoting low carbon innovation that works to a long-term goal.

\section{Integrate and Manage Windows of Opportunity}

The destabilization of the regime creates windows of opportunity for radical niche innovations to break through, compete with the existing regime and eventually create a new, more sustainable regime (Geels, 2010). Like the technological windows, provide particularly favorable opportunities for the innovation or diffusion of technological alternatives, policy windows open through focusing events, such as a crisis or disaster, or because of a change in the political stream, such as a change in priorities for a new administration. With the concept of system transformation, the opening of technological and policy windows can be better aligned since policy instruments can have a 'technological content' that changes with different transition levels. In the niche level, policymakers should promote a diversity of potential new technology policies are also able to create a technological window by creating a market and other conditions for a new option to succeed; while selecting from a variety of sustainable paths innovation, policymakers should promote risk assessment and policy experiments to avoid rush selection between a number of potential new technological options; after a certain sustainable path is selected policies are to be designed to ease the transition between an old and new technological option (Nill, 2003; 2004; Nill and Sartorius, 2004).

\section{Guide the Direction of Market Formation}

According to system transformation, path dependencies are present. Policies that guide supply- and demand-side search processes such as direct and indirect demand-pull measures can be an important prerequisite for eventual market formation. Policymakers should aim to facilitate mass-production of socio-beneficial technological artifacts and fading-off the use of unsustainable technologies through implementing a coherent, integrated policy mix.

Besides indirect demand-pull measures, direct demand-pull instruments are in need to support market formation to complement technology policies until upscaling stages. An up-scaling of technologies is necessary to develop economies of scale and learning effects (Purkus et al., 2018). Hereafter scaling up the production of new energy with improvement in technology and reduction in cost makes it competent enough to overcome the barriers not only from components of existing technology but also from the overall system in which it is embedded.

\section{Social-Technological Landscape}

The social-technological landscape includes factors of spatial structures (e.g., urban layouts), political ideologies, societal values, beliefs, concerns, the media landscape and macro-economic trends, which beyond the control of individual actors. However, these nontechnological factors are important preconditions for sustainability. Thus better understanding the structure of landscape-level and the multilevel dynamics through 
the three levels can guide policymaker's attention to relevant issues, identify policy windows, and develop appropriate instruments.

Arranz (2017) classified the impact of the landscape into three elements as scientific acquired indicators (e.g., $\mathrm{CO}_{2}$ concentrations, oil scarcity), unintentional pressure (e.g., macro-political trends, trends in the perception of the nature), intentional pressure (e.g., climate policy deliberately attempts to tackle climate change). The impact of landscape on regimes generally includes both destabilizing and stabilizing landscape pressures (Geels, 2012). Examples of destabilizing pressure are climate change, increased traditional energy price, energy crisis for non-renewable energy (the belief that the world will run out of oil in the far future), stronger policy action with renewable alternatives. The stabilizing pressure comes from societal characteristics and developments. We cited the auto-mobility system analysis in the United Kingdom and the Netherlands by (Geels, 2012) and presented as a stabilizing factors example. For the auto-mobility system in the United Kingdom and the Netherlands, the landscape trends stabilizing auto-mobility regime are a cultural preference for the private property than carsharing scheme, a cultural preference for time-saving, urban structures with a separation of work and home, cultural values such as freedom, choice, wealth and status, macro-economic growth, shift towards a network society. This example provides a picture of how the landscape trends can stabilize the regime level and slow down low carbon transitions.

\section{Discussion}

As more analysis and research on the socioeconomical transitions to low-carbon technologies with system thinking will be documented, policymakers can exchange lessons and information regarding innovation systems in a concerted policy language. Comparative studies on how system transformation functions at national, regional and sectorial levels between countries could reveal problems occurring in current systems and help identify opportunities for public policy interventions and allow for progressive policy "leapfrogging", accelerating improved policy intervention.

There's value in modulating the evolutionary paths of sustainable technology systems in national policy program experiments, case studies, or pilot projects like EU and international experience and approaches in other countries to mitigate unwanted policy outcomes. A more transparent and regulatory process could improve the efficacy of policy learning within energy and innovation policy through review and learning and clearer criteria for judging the success or failure of policy instruments within a stronger long-term strategic framework. Policy learning is especially important for inclusive innovation (Heeks et al., 2014), developing and nurturing alternative technological interventions designed to mitigate poverty, inequality and social exclusion, for instance, through local experimentation (Berkhout et al., 2017).

\section{Conclusion}

Increasing $\mathrm{CO}_{2}$ emission has marked every step of economic development in the traditional energy system. We've arrived at the top of the point to accelerate the transformation from the current system to a radical novel sustainable energy one. Since the energy policy is on no larger scale that needs more comprehensive technologies and policy instruments, the concept of "system transformation" with an innovation system perspective can be quite helpful for energy policymakers.

It can not only build up the cooperative relationship of the public and private actors by a concerted goal but also mix a variety of technologies and policy instruments in a quite rich way. The uncertainties in long-term low carbon transitions will be tackled. Furthermore, the sticky carbon lock-in can be addressed in the long run by giving incentives to the emergence of new technology and stimulating the improvement and adoption of mature technology. Finally, by monitoring and evaluation of policy implementation using the same system thing, policy-making processes could be enhanced and increasing policy process enrichment. The capacity to anticipate is being improved and alternatives can be developed in a timely fashion (Box 2).

\section{Box 2}

How can concept of system transformation assist policymakers in designing appropriate policy package?

1. Developing an appropriate policy mix

2. Dealing with uncertainty, portfolio approach for transition paths

3. Facilitating mutual learning process between policy makers and broader public/private sectors

4. Aligning technological and policy windows: Making policy instruments coherent to different level of technological transition

5. Identifying system failure as policy intervention signpost

6. Presenting wider landscape context and interaction dynamics for better understanding of system setbacks

The policy recommendation is always contextdependent. We summarize the principles emphasized in this study (Box 3) for developing effective innovation policy instruments. 


\section{Box 3}

Low carbon transition supporting policy principals derived from system transformation:

1. Prepare appropriate mix of policy instruments coherent to different level of transition systems

(i). Technology-specific direct demand-pull instruments

(ii). Technology-neutral indirect demand-pull instruments

(iii).Changing market rules for decarburization through, e.g., a carbon tax or pricing;

(iv). Reduced support (such as tax breaks or subsidies) for high-carbon technologies

2. Building networks insuring broader participation:

(i). Promoting public/private institutional structures to enhance regulator/regulated relationships and stakeholder activities

(ii). Promote knowledge development and resources mobilization within networks of policy makers, public sector and private firms

3. Using portfolio approach for niche development:

(i). Dealing with uncertainties

(ii). Nurturing various transition paths rather than using technology-push policy

4. Facilitate low carbon transitions for inclusive development:

(i) Promote technology transfer to decarbonize economy

(ii) Reconcile development and sustainability

\section{Funding}

This research did not receive any specific grant from funding agencies in the public, commercial, or not-forprofit sectors.

\section{Ethics}

This article is original and contains unpublished material. The corresponding author confirms that all of the other authors have read and approved the manuscript and no ethical issues involved.

\section{References}

Arranz, A. M. (2017). Lessons from the past for sustainability transitions? A meta-analysis of sociotechnical studies. Global environmental change, 44, 125-143.
Berkhout, F., Wieczorek, A. J., \& Raven, R. (2017). Avoiding environmental convergence: a possible role for sustainability experiments in latecomer countries?. Institutions and Economies, 367-385.

Charles, E. (2005). Systems of innovation: perspectives and challenges. The new Oxford Handbook of Innovation.

Djalante, R., \& Djalante, S. (2012). Derk Loorbach: Transition management, new mode of governance for sustainable development.

Foxon, T. J., \& Pearson, P. J. (2007). Towards improved policy processes for promoting innovation in renewable electricity technologies in the UK. Energy Policy, 35(3), 1539-1550.

Foxon, T., \& Pearson, P. (2008). Overcoming barriers to innovation and diffusion of cleaner technologies: some features of a sustainable innovation policy regime. Journal of cleaner production, 16(1), S148-S161.

Gallagher, K. S., Grübler, A., Kuhl, L., Nemet, G., \& Wilson, C. (2012). The energy technology innovation system. Annual review of environment and resources, 37, 137-162.

Geels, F. W. (2002). Technological transitions as evolutionary reconfiguration processes: a multi-level perspective and a case-study. Research policy, 31(8-9), 1257-1274.

Geels, F. W. (2004). From sectoral systems of innovation to socio-technical systems: Insights about dynamics and change from sociology and institutional theory. Research policy, 33(6-7), 897-920.

Geels, F. W. (2010). Ontologies, socio-technical transitions (to sustainability) and the multi-level perspective. Research policy, 39(4), 495-510.

Geels, F. W. (2012). A socio-technical analysis of lowcarbon transitions: introducing the multi-level perspective into transport studies. Journal of transport geography, 24, 471-482.

Geels, F. W., \& Schot, J. (2007). Typology of sociotechnical transition pathways. Research policy, 36(3), 399-417.

Geels, F. W., Schwanen, T., Sorrell, S., Jenkins, K., \& Sovacool, B. K. (2018). Reducing energy demand through low carbon innovation: A sociotechnical transitions perspective and thirteen research debates. Energy research \& social science, 40, 23-35.

Geels, F. W., Sovacool, B. K., Schwanen, T., \& Sorrell, S. (2017). The socio-technical dynamics of lowcarbon transitions. Joule, 1(3), 463-479.

Heeks, R., Foster, C., \& Nugroho, Y. (2014). New models of inclusive innovation for development.

Hekkert, M. P., \& Negro, S. O. (2009). Functions of innovation systems as a framework to understand sustainable technological change: Empirical evidence for earlier claims. Technological forecasting and social change, 76(4), 584-594. 
Holtz, G., Xia-Bauer, C., Roelfes, M., Schüle, R., Vallentin, D., \& Martens, L. (2018). Competences of local and regional urban governance actors to support low-carbon transitions: Development of a framework and its application to a case-study. Journal of Cleaner Production, 177, 846-856.

ICEPT, E4Tech. (2003). The UK innovation systems for new and renewable energy technologies. Report for UK http://www.oecd.org/science/inno/32163700.pdf

Jänicke, M., \& Jacob, K. (2005). Ecological modernisation and the creation of lead markets. In Towards environmental innovation systems (pp. 175-193). Springer, Berlin, Heidelberg.

Jolly, S., Raven, R., \& Romijn, H. (2012). Upscaling of business model experiments in off-grid PV solar energy in India. Sustainability science, 7(2), 199-212.

Kanger, L., Sovacool, B. K., \& Noorkõiv, M. (2020). Six policy intervention points for sustainability transitions: A conceptual framework and a systematic literature review. Research Policy, 49(7), 104072.

Kemp, R., Loorbach, D., \& Rotmans, J. (2007). Transition management as a model for managing processes of co-evolution towards sustainable development. The International Journal of Sustainable Development \& World Ecology, 14(1), 78-91.

Kern, F. (2011). Ideas, institutions and interests: explaining policy divergence in fostering 'system innovations' towards sustainability. Environment and Planning C: Government and Policy, 29(6), 1116-1134.

Kern, F. (2012). Using the multi-level perspective on socio-technical transitions to assess innovation policy. Technological Forecasting and Social Change, 79(2), 298-310.

Kern, F., \& Smith, A. (2008). Restructuring energy systems for sustainability? Energy transition policy in the Netherlands. Energy policy, 36(11), 4093-4103.

Köhler, J., Geels, F. W., Kern, F., Markard, J., Onsongo, E., Wieczorek, A., ... \& Fünfschilling, L. (2019). An agenda for sustainability transitions research: State of the art and future directions. Environmental Innovation and Societal Transitions, 31, 1-32.

Negro, S. O., Alkemade, F., \& Hekkert, M. P. (2012). Why does renewable energy diffuse so slowly? A review of innovation system problems. Renewable and Sustainable Energy Reviews, 16(6), 3836-3846.
Nieto, A., Roberts, S. P. M., Kemp, J., Rasmont, P., Kuhlmann, M., García Criado, M., ... \& De Meulemeester, T. (2014). D. 2014. European red list of bees. Luxembourg: Publication Office of the European Union.

Nill, J. (2003, January). Windows of sustainability opportunities-determinants of techno-economic time windows and conditions under which environmental innovation policy can utilise them. In Paper for the DRUID PhD Winter 2003 Conference.

Nill, J. (2004). Time strategies of transitions and the transformed role of subsidies as environmental innovation policy instrument. In Proceedings of the 2003 Berlin Conference on the Human Dimensions of Global Environmental Change, Environmental Policy Research Centre: Berlin (pp. 295-307).

Nill, J., \& Sartorius, C. (2004, May). Innovation policy towards sustainability-the preparation, use, creation and maintenance of "time windows". In paper for the international conference Innovation, Sustainability and Policy (pp. 23-25).

Onsongo, E. (2019). Institutional entrepreneurship and social innovation at the base of the pyramid: the case of M-Pesa in Kenya. Industry and Innovation, 26(4), 369-390.

Purkus, A., Hagemann, N., Bedtke, N., \& Gawel, E. (2018). Towards a sustainable innovation system for the German wood-based bioeconomy: Implications for policy design. Journal of Cleaner Production, 172, 3955-3968.

Rip, A., \& Kemp, R. (1998). Technological change. Human choice and climate change, 2(2), 327-399.

Rotmans, J., Kemp, R., \& Van Asselt, M. (2001). More evolution than revolution: transition management in public policy. Foresight-The journal of future studies, strategic thinking and policy, 3(1), 15-31.

Smith, A., \& Seyfang, G. (2013). Constructing grassroots innovations for sustainability. Global Environmental Change, 23(5), 827-829.

Smith, A., Stirling, A., \& Berkhout, F. (2005). The governance of sustainable socio-technical transitions. Research policy, 34(10), 1491-1510.

Unruh, G. C. (2000). Understanding carbon lock-in. Energy policy, 28(12), 817-830. 